\title{
Contact and Inter-laminate Stresses Minimization in Laminated Leaf Springs
}

\author{
Zaid S. Hammoudi \\ Department of Mechanical Engineering, College of Engineering, University of Diyala, Iraq \\ *corresponding author: email address: zshaaa@yahoo.com
}

\begin{abstract}
A study, on the contact stresses and interlaminate stress distributions in laminated leaf springs, is presented in this research. Several configurations and models of leaf springs are analyzed by finite element method. The aim is to find a configuration, which provides minimum values of contact stresses and inter-laminate stresses, for the same spring constant and loaddeflection response. Results of the analyses show that making certain types of cuts in leaf springs could provide better designs than original unmodified springs, and leads to reduction in contact and inter-laminate stresses. This reduction in stresses is expected to increase the service life of leaf springs.
\end{abstract}

Keywords: Leaf springs, FEM, Contact stress, Design optimization.

\section{Paper History:}

(Received: 18/9/2017; Accepted: 29/10/2017)

\section{Introduction}

Leaf springs are widely used in suspension systems of heavy truck and some cars. The design of these types of spring is simple and well known. Because of its configuration, contact stresses arise between leafs during service. These stresses, along with dry sliding between leafs during operation, causes wear and surface fatigue which would reduce the service life of the spring. Due to the operation conditions of leaf springs, it is not easy to maintain some type of lubrication between leafs. So to reduce wear arising on leafs due to dry sliding friction, it is preferable to minimize the contact pressure.

Many studies and researches are published on leaf springs using experimental and numerical methods. Most of them are related to classical stress analysis of springs, such as those in references $[1,2,3,4$, and 5]. Some researches are directed towards using composite materials iv- instead of steel to reduce total weight and cost of spring. Sample of such results are in references [6,7, and 8]. There are researches on fatigue failure of leaf springs. Sample of them are in references [9,10,11, and 12]. Some of the researches on dynamic analysis of leaf springs, which are related to response and vibration of springs due to external loads, are in listed in references [13 and 14].

The current study presents an investigation on contact stresses between leaf springs during service. Besides, making some simple modifications on leafs of original classical unmodified springs. A number of models of leaf springs are analyzed. Several types of modifications on original classic springs are made aiming to reduce contact and inter-laminate stresses. Results show that it is possible to reduce these stresses with appropriate modifications. To author's knowledge, this matter has not been studied or analyzed by other researchers, and no similar contribution has been published.

\section{Finite element modeling}

Two models of leaf springs are analyzed by the finite element method, six- leaf spring model, and four- leaf spring model. The analyses are carried out using Ansys 15 software. For simplicity, accuracy and to reduce run time, two dimensional plane stress models are build, as shown in Figure 1. Due to symmetry only half of the springs are modeled. The boundary conditions considered are as follows;

i- The line of symmetry is considered fixed in the $\mathrm{x}$ - direction, and free to move on the $\mathrm{y}$ direction,

ii- The upper right corner point of the top leaf is fixed in the $y$ - direction and free to move in the $\mathrm{x}$ - direction,

iii- The lower left corner point of the lower leaf spring is set to move upward (in the ydirection) by a certain value of displacement (load). 


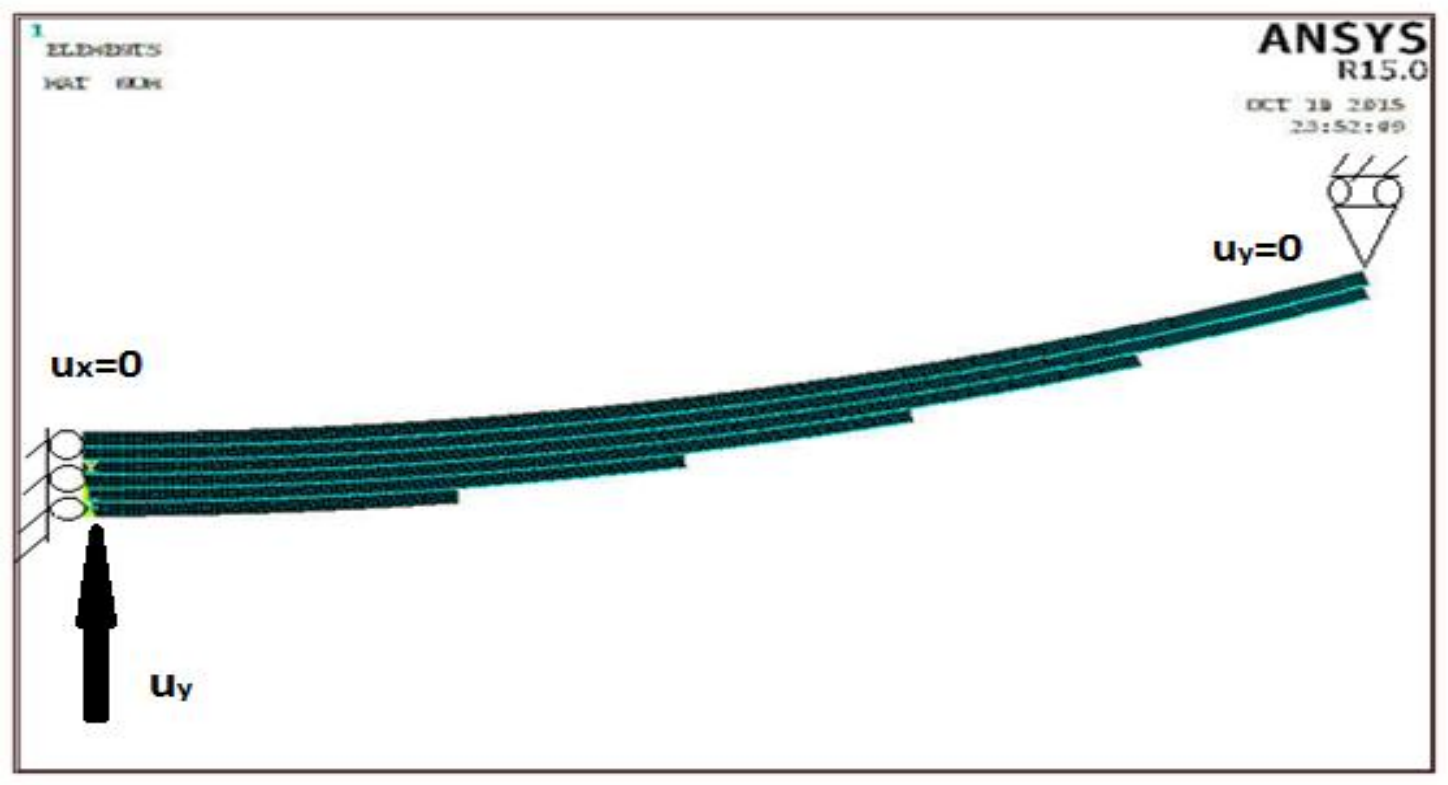

Figure 1: Modeling and boundary conditions of six-leafs spring

Realistic general contact configuration between leafs is considered, with the coefficient of friction is set to be 0.3 [15]. Ansys element types used in the analysis are "Plane 182" for modeling of leaf springs, and "Targe 169" and "Conta 172" for modeling contact regions between leaf springs. Non- linear analysis with large deformation effects have been considered in all analysis. In each model in the analysis, a load of upward displacement is applied at the midpoint of the full spring (lower left corner of the analyzed halfmodel). The force load is obtained from the results of analysis as the reaction force at the point of application the displacement load in the y-axis. The analysis is carried out by gradual application of load in several hundreds of load sub-steps until convergence of solution is achieved. All leafs are assumed to have same curvatures on assembly, so that they are stress- free at start of analysis. There are types of springs where leafs might not have same curvature, so they have initial stress during assembly. Such cases can be analyzed separately, and expected to result similar findings of current study.

\section{Results and discussion}

The characteristics of the analyzed springs are shown in Table 1. In this research, a general study on some of the possible modifications on traditional leaf springs is presented. The findings of this study can be withdrawn to most of leaf springs on practical use. For this reason, the specific detailed dimensions of springs and modifications made are not presented.

Table 1 Specifications of analyzed leaf springs 1

\begin{tabular}{|c|c|c|}
\hline 1. Item & 2. $\quad$ Six- leafs spring & 3. $\quad$ Four- leafs spring \\
\hline Total length of the spring & $790 \mathrm{~mm}$ & 6. $\quad 780 \mathrm{~mm}$ \\
\hline Free camber & 8. $\quad 70 \mathrm{~mm}$ & 9. $60 \mathrm{~mm}$ \\
\hline 10. Number of full leaves & 11. 2 & $12 . \quad 1$ \\
\hline 13. Number of graduated leaves & 14. 4 & 15. 3 \\
\hline 16. Thickness of the leaf & 17. $6 \mathrm{~mm}$ & 18. $9 \mathrm{~mm}$ \\
\hline 19. Width of the leaf & $20 . \quad 60 \mathrm{~mm}$ & 21. $90 \mathrm{~mm}$ \\
\hline 22. Young modulus & 23. $210 \mathrm{GPa}$ & 24. $210 \mathrm{GPa}$ \\
\hline 25. Poisson's ratio & 26. 0.3 & 27. 0.3 \\
\hline 28. Ultimate tensile strength & 29. $1962 \mathrm{MPa}$ & 30. $1962 \mathrm{MPa}$ \\
\hline 31. Tensile yield strength & 32. $1500 \mathrm{MPa}$ & 33. $1500 \mathrm{MPa}$ \\
\hline
\end{tabular}




\subsection{Six- leafs model}

The model of this spring is shown in Figure 1. A total of 13104 elements are used in the analysis. The analysis on all spring models are carried out by gradual application of displacement load until maximum allowable displacement is reached. On this spring maximum displacement is $70 \mathrm{~mm}$. Figures 2 and 3 show the resulting contact pressure (stress) and von Mises stress, respectively. It is clear that the contact stresses are concentrated at the ends of the generated leafs, with a maximum value of $53.14 \mathrm{MPa}$. These high levels of contact stresses are the main cause of surface wear of the leaf springs at these areas. To reduce the values of these stresses, with maintaining the original characteristics of the spring, several modifications are tested. The cause of the high localized contact stresses at the ends, are resulted from the sudden change in the total thickness of the leaf spring at these areas. The modifications are directed towards graduating the change of the thickness. The first modification analyzed is shown in Figure 4. As shown, inclined cuts are made at ends of leafs to make rather gradual change of the whole thickness of the spring. Results of this model are shown in Figures 5 and 6 . It is clear that the maximum contact stress is significantly reduced to a value of 12.8 $\mathrm{MPa}$. That is reduced to a value of $24 \%$ of that of the original unmodified model. Maximum von Mises stresses are also relieved.
The second modification attempt is shown in Figure 7. Here two, half- circular cuts have been made on the original spring. Radii of cuts are (3 $\mathrm{mm})$ near the end of leafs, and $(1.5 \mathrm{~mm})$ at certain distances. Results of this model are shown in Figures 8 and 9. It can be seen that contact stresses had minor reduction. Von Mises stresses are almost the same of the original model.

Third modification attempt is shown in Figure 10. Here, an elliptical cut in each generated leaf is made close to its end. The elliptical cut is simulated as a circle of radius of $40 \mathrm{~mm}$, where the maximum cut depth is about half of leaf thickness. Results of this analysis, Figures 11 and 12 , show reductions in contact stresses to about half of that of unmodified spring. Von Mises stresses are also mildly reduced through this modification.

Figure 13 shows the load- deflection response of analyzed springs. This graph represents the response of the analyzed halve spring model. So the total load of full spring is twice of the load on this model. The scale (spring constant) of the whole spring is then slope of the load-deflection response multiplied by two. It is clear that all above modifications on spring did not cause any significant change in spring scale. The response of spring to external load is about the same of original unmodified spring, for all modifications made.

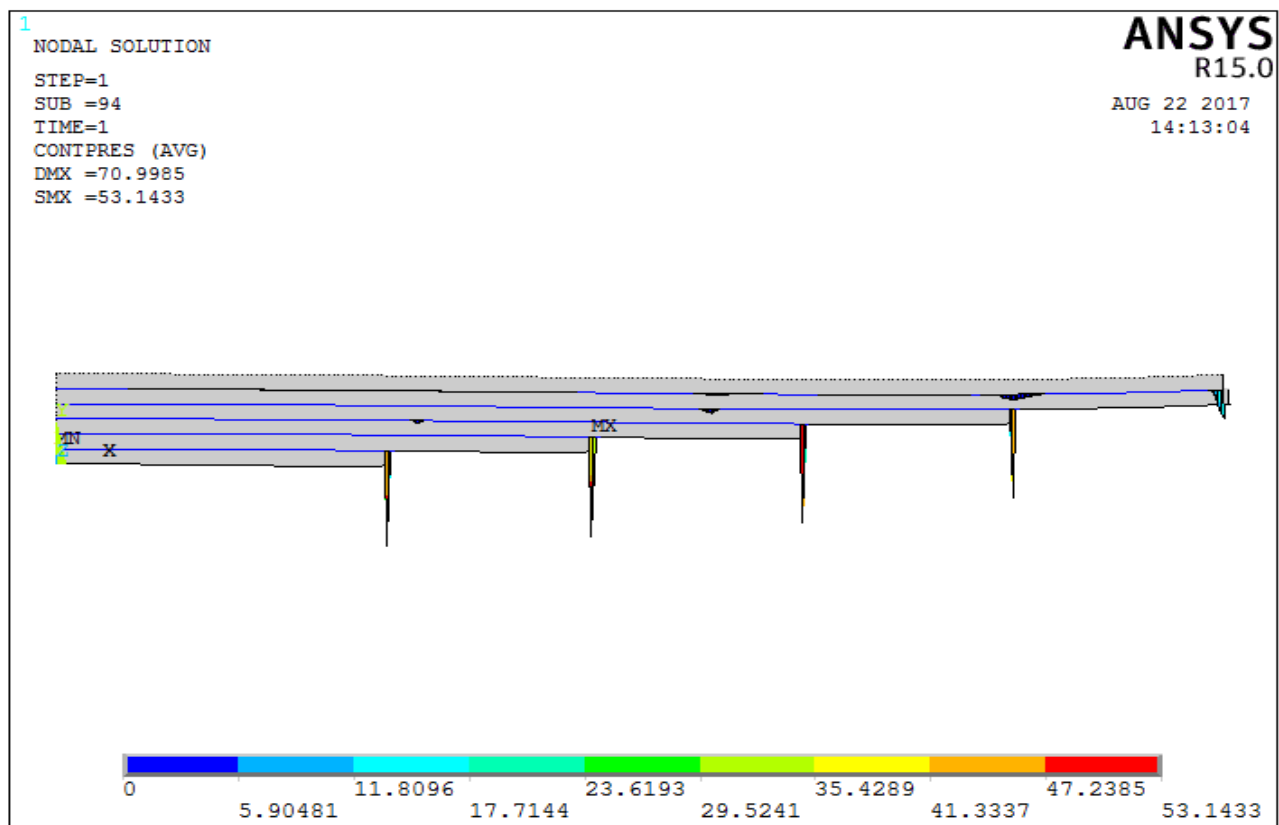

Figure 2: Contact pressure of six-leafs spring 


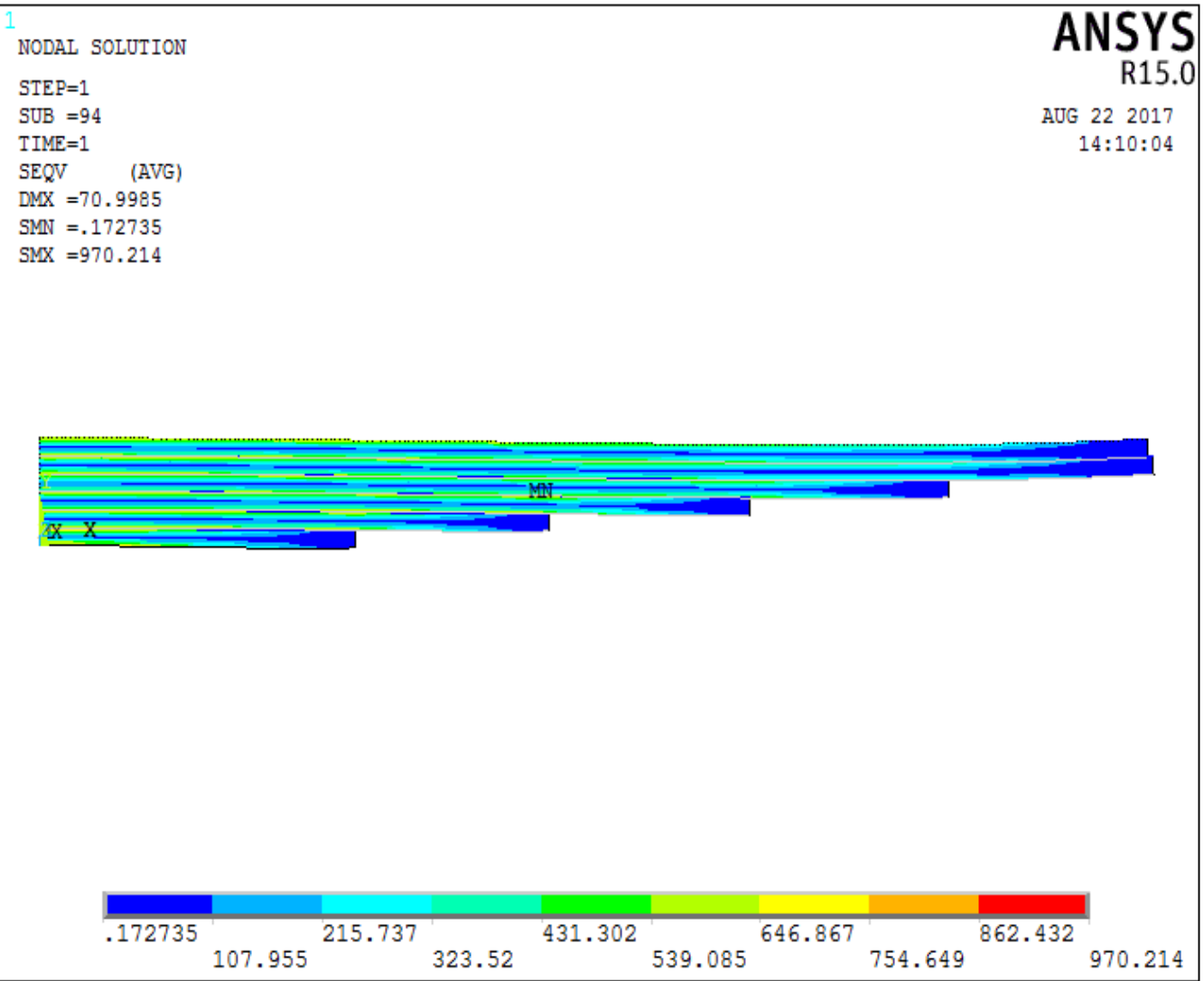

Figure 3: Von Mises stress of six-leafs spring

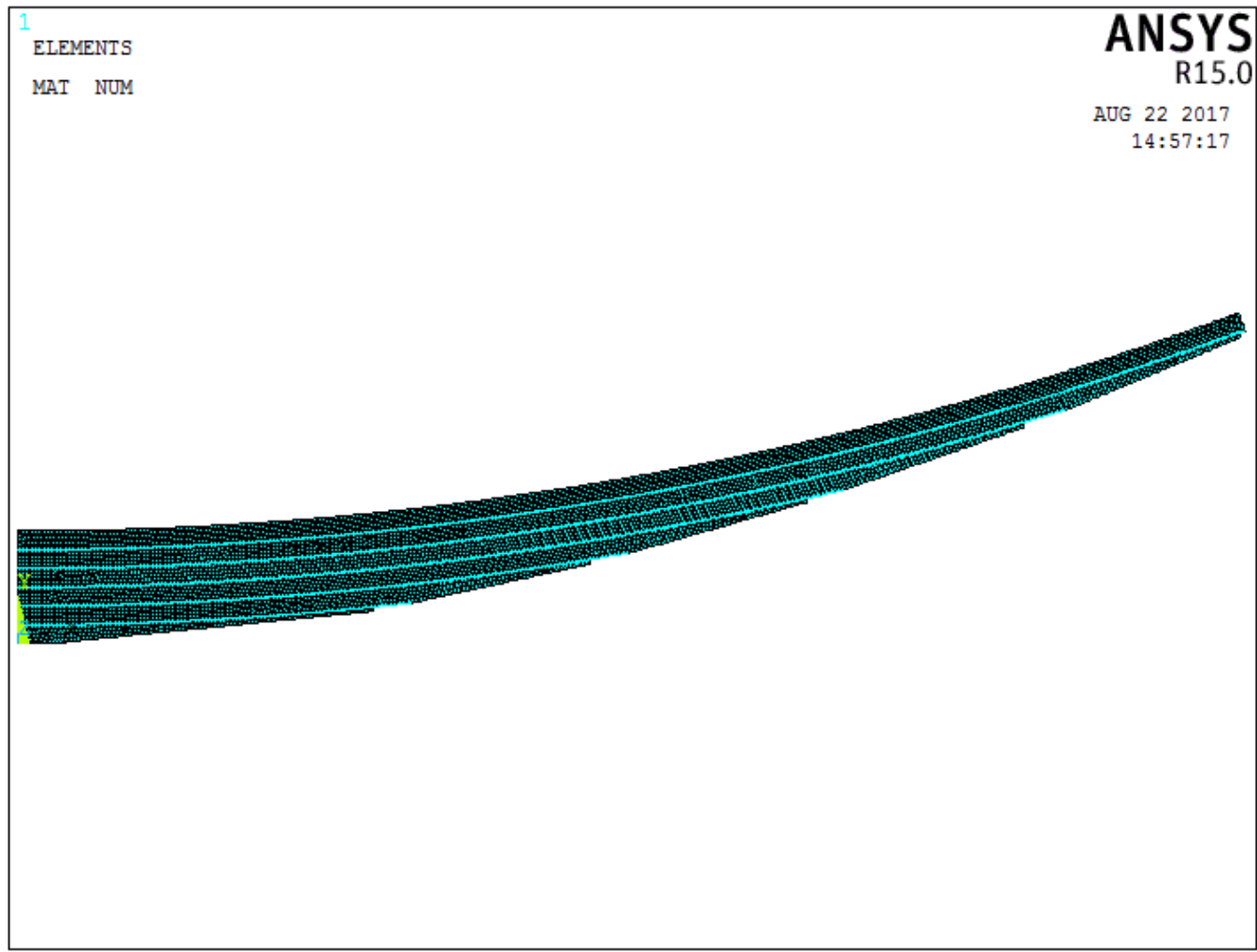

Figure 4: Six-leafs spring with inclined cut 


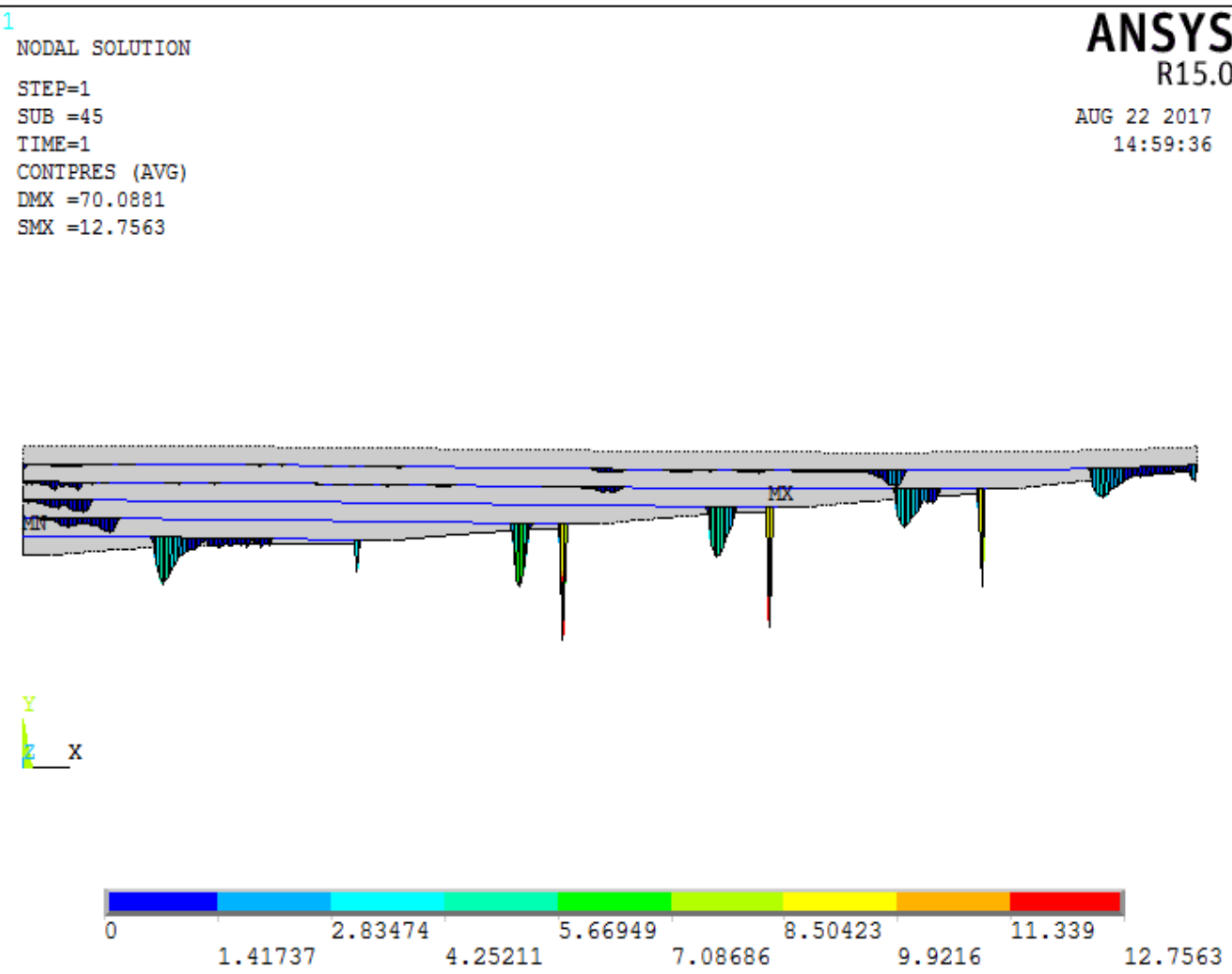

Figure 5: Contact pressure of six-leafs spring with inclined cut

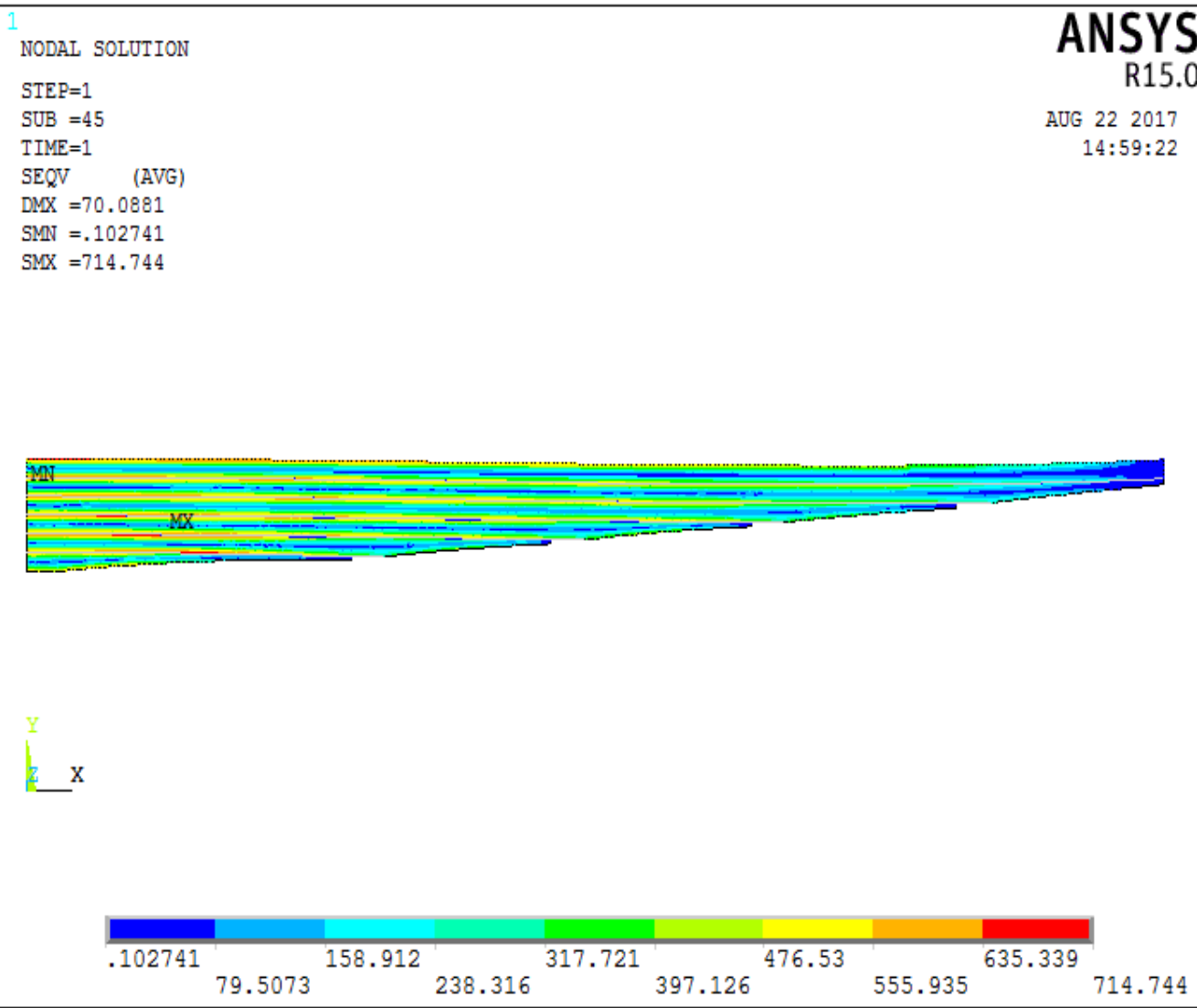

Figure 6: Von Mises stress of six-leafs spring with inclined cut 


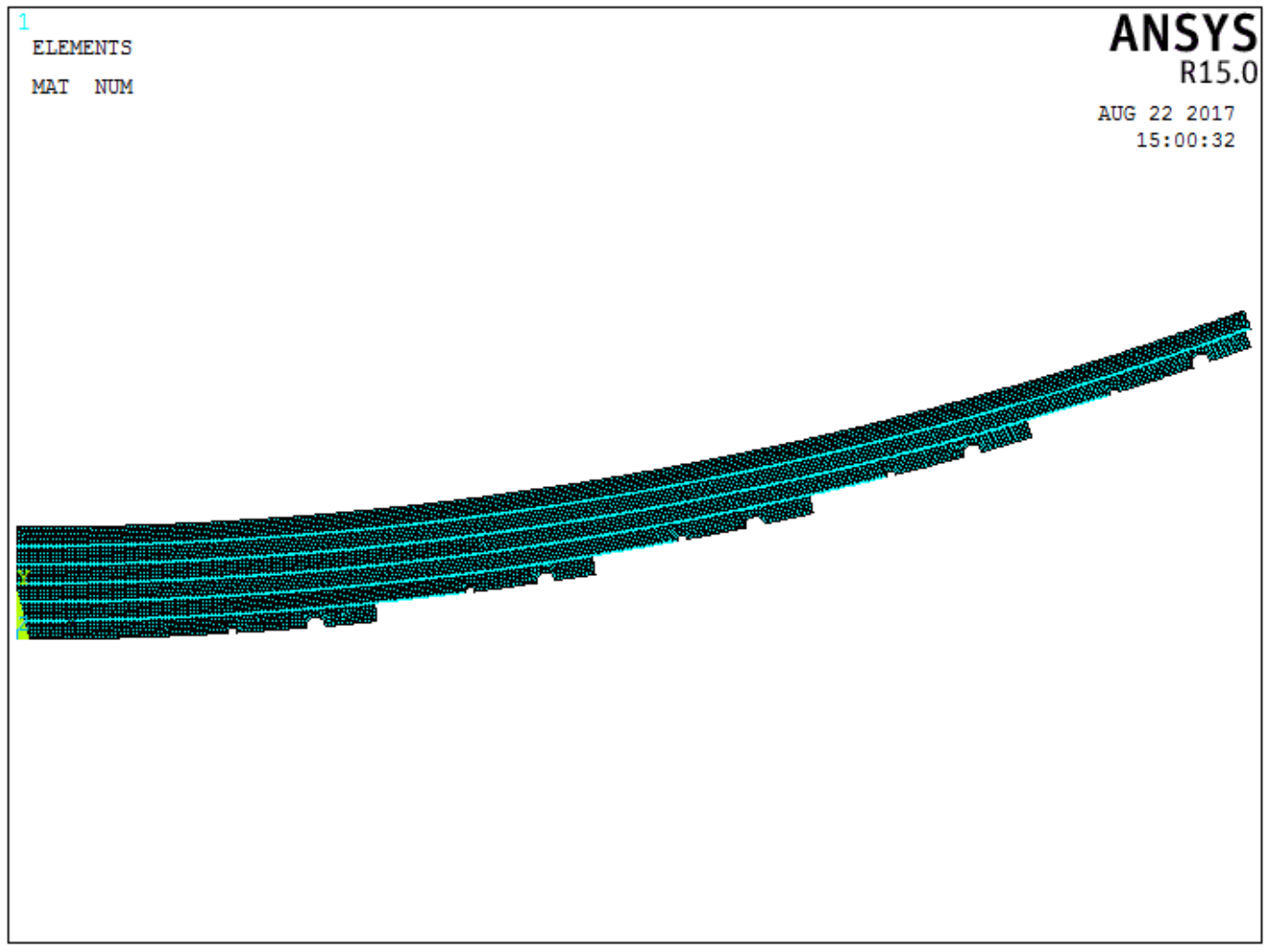

Figure 7: Six- Leafs spring with circular cuts

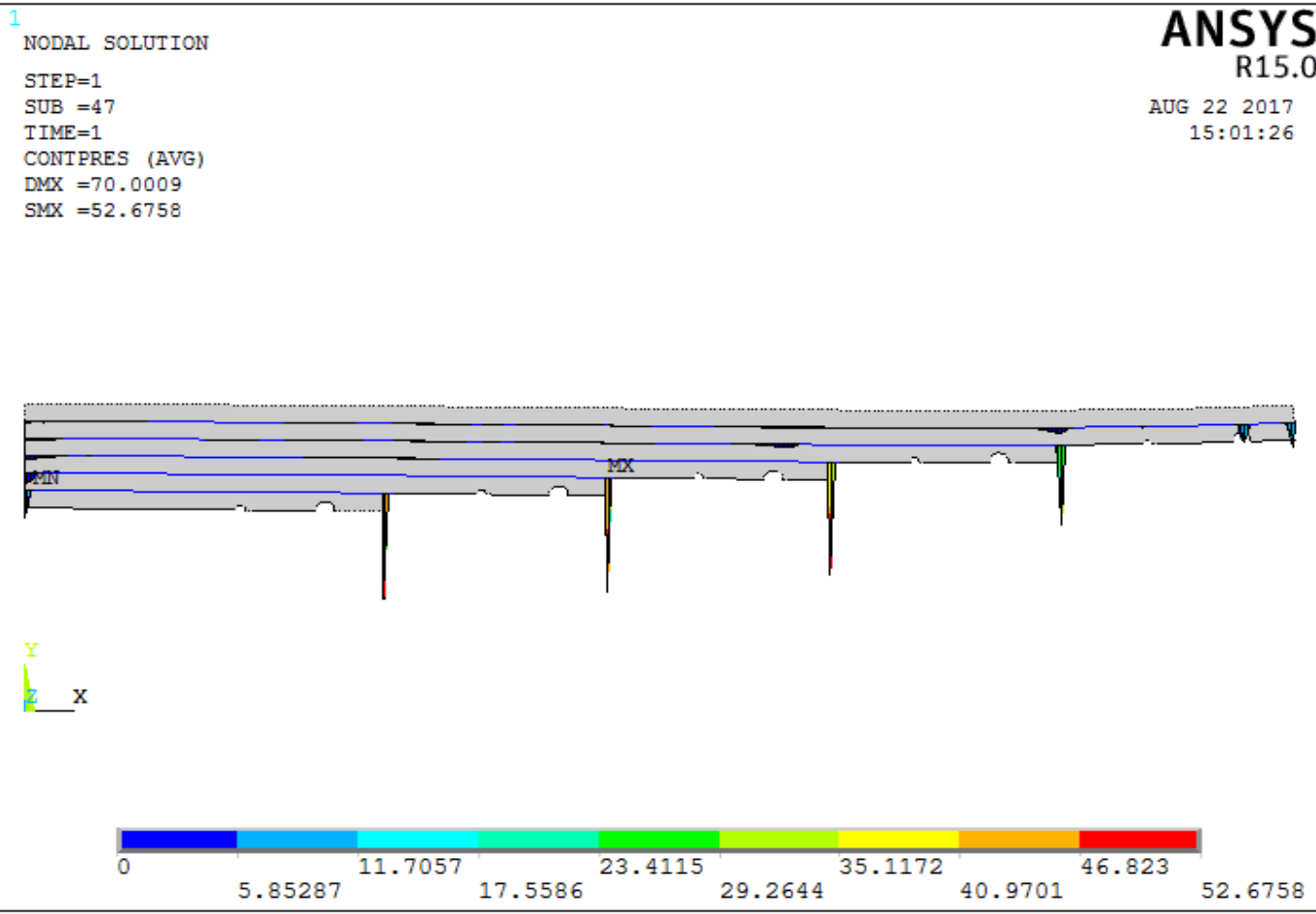

Figure 8: Contact pressure of six-leafs spring with circular cuts 


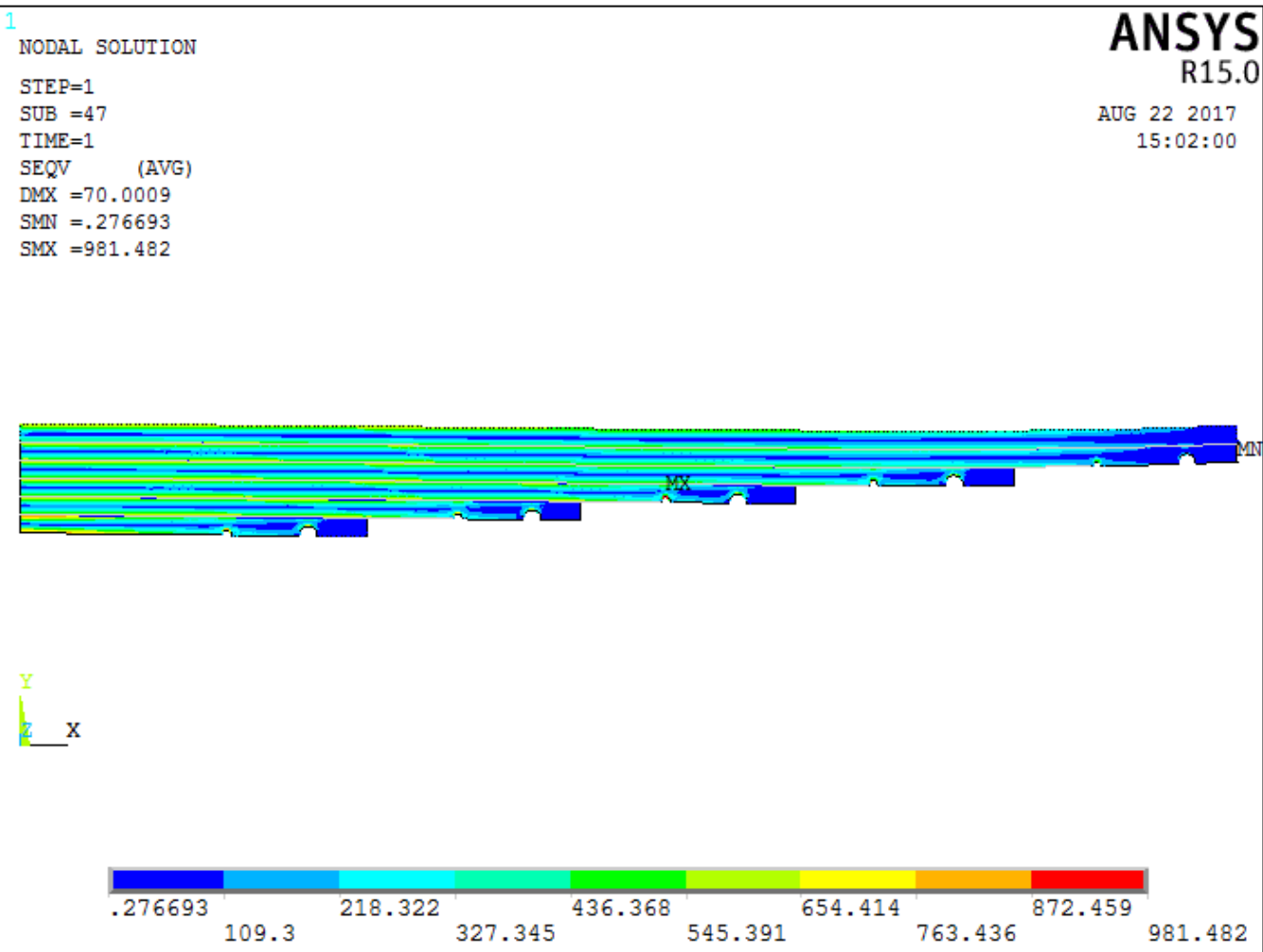

Figure 9: Von Mises stress of six-leafs spring with circular cuts

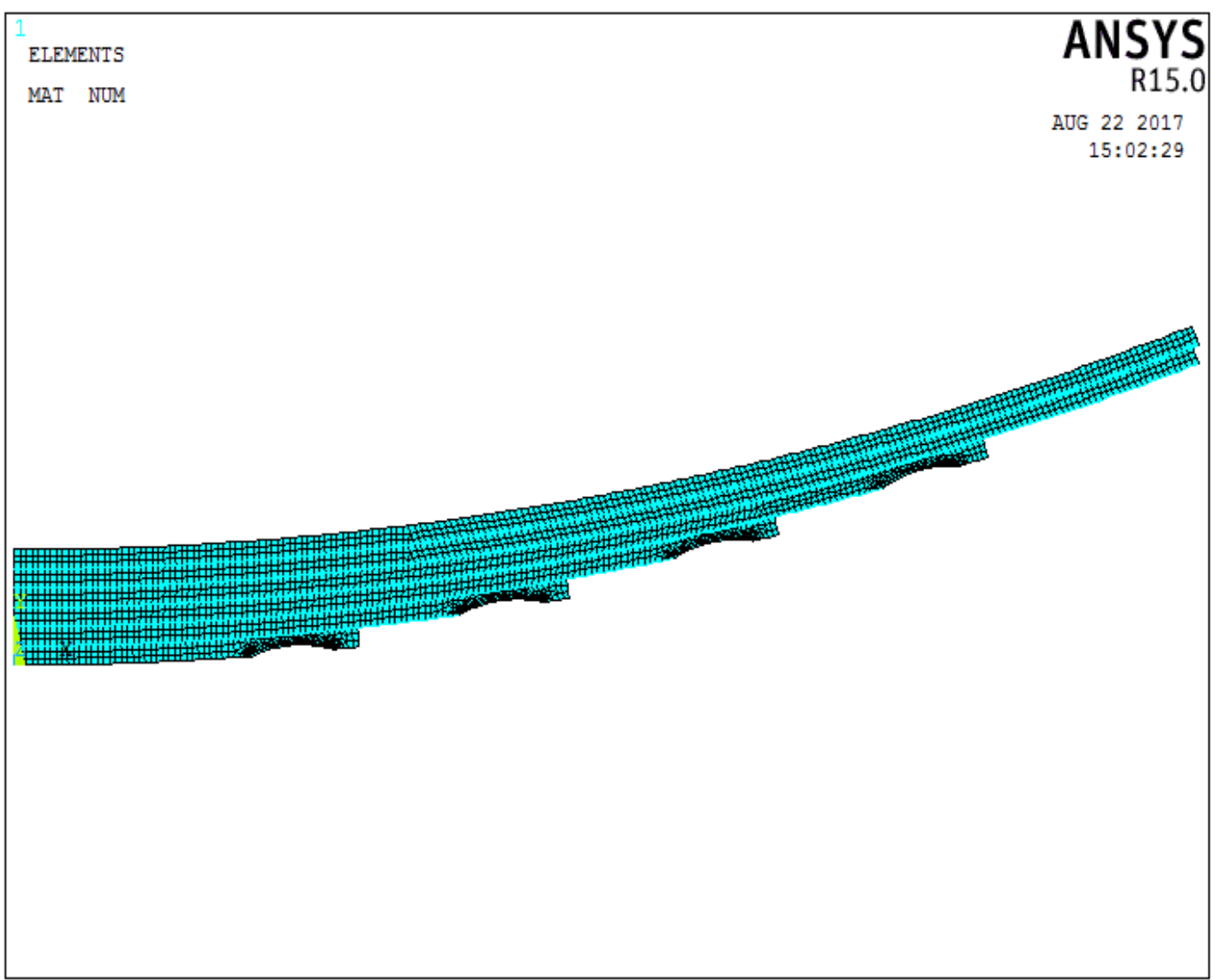

Figure 10: Six-leafs spring with an elliptical cut 


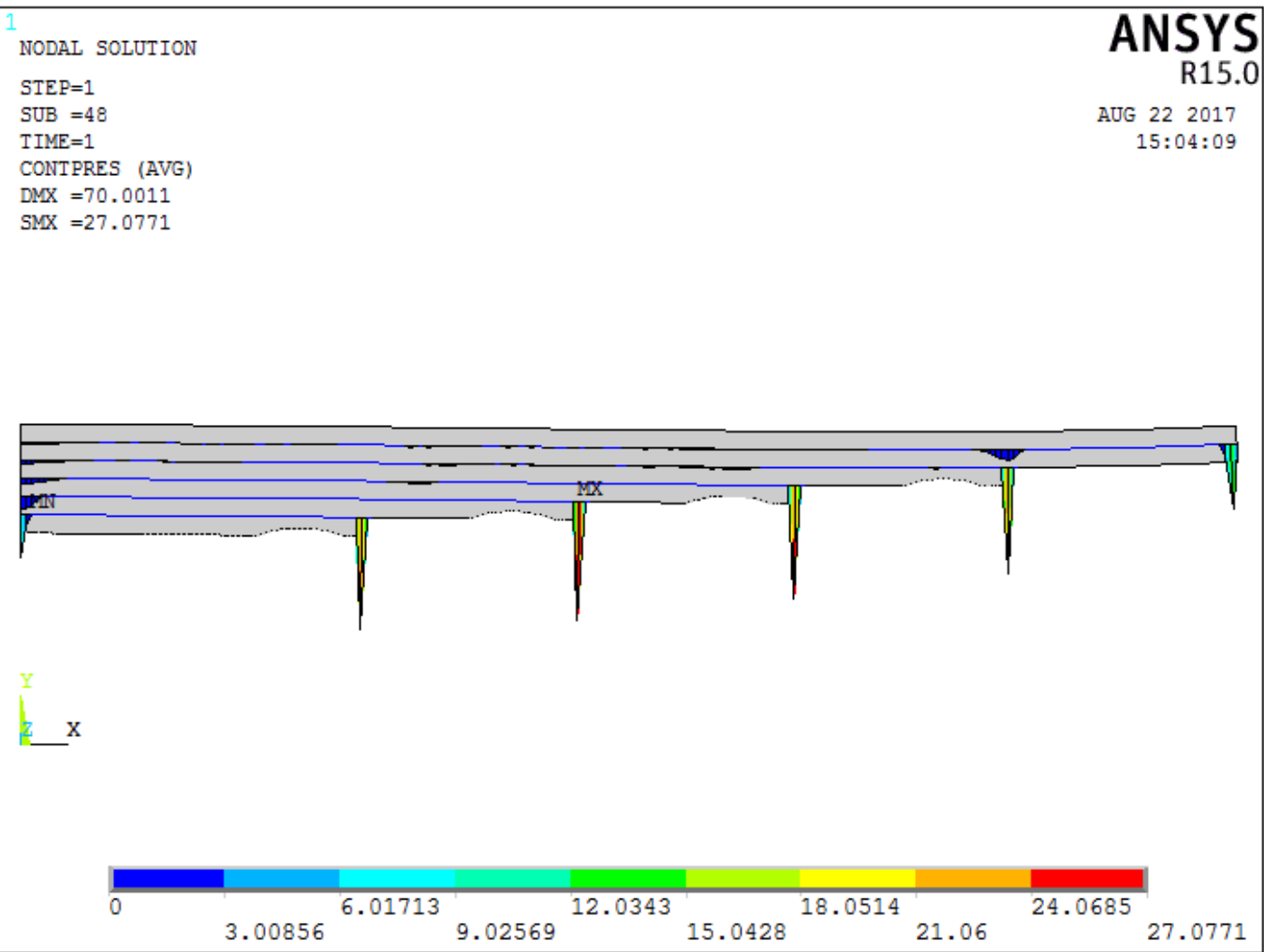

Figure 11: Contact pressure of six-leafs spring with elliptical cut

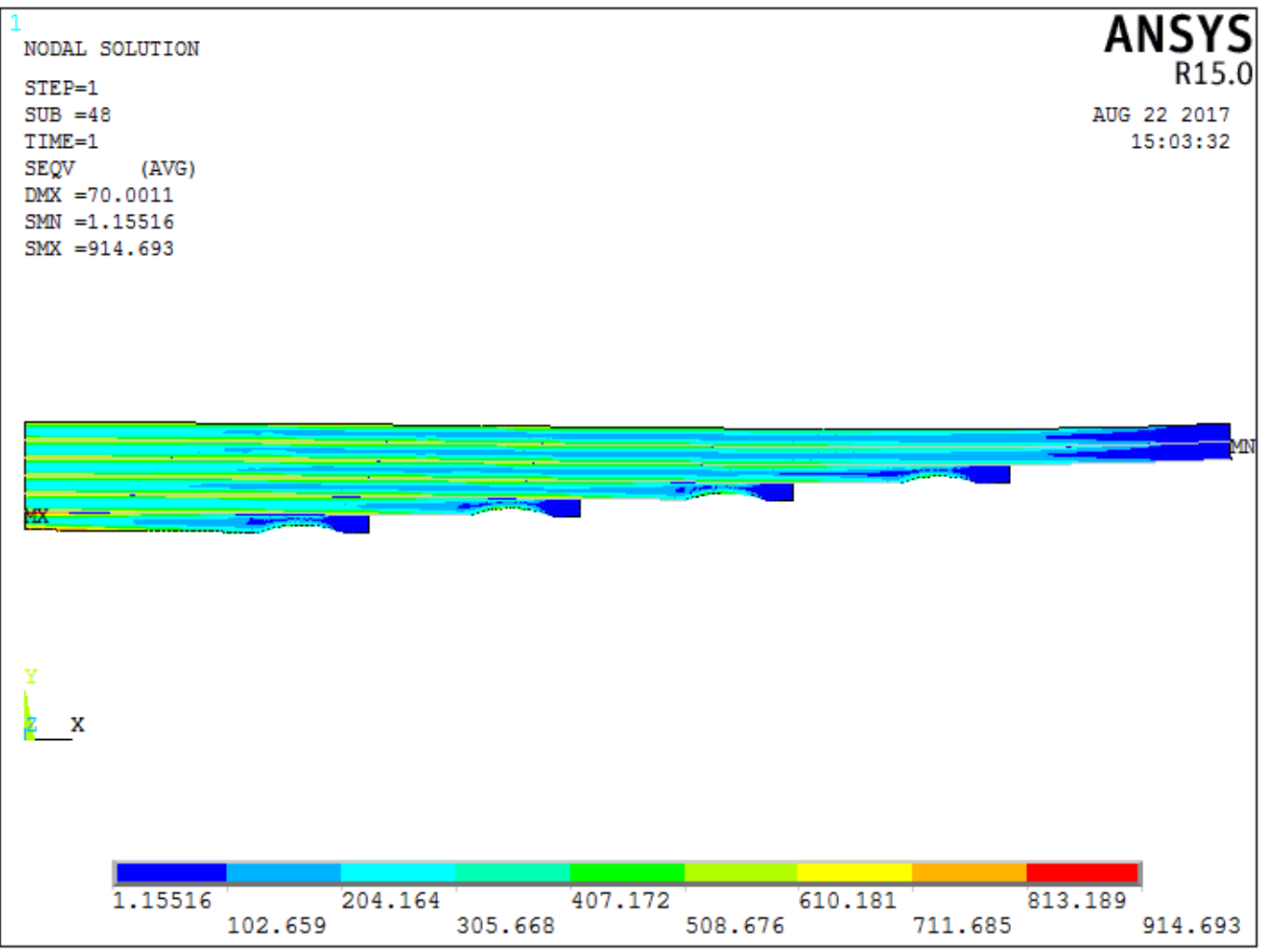

Figure 12: Von Mises stress of six-leafs spring with elliptical cut 


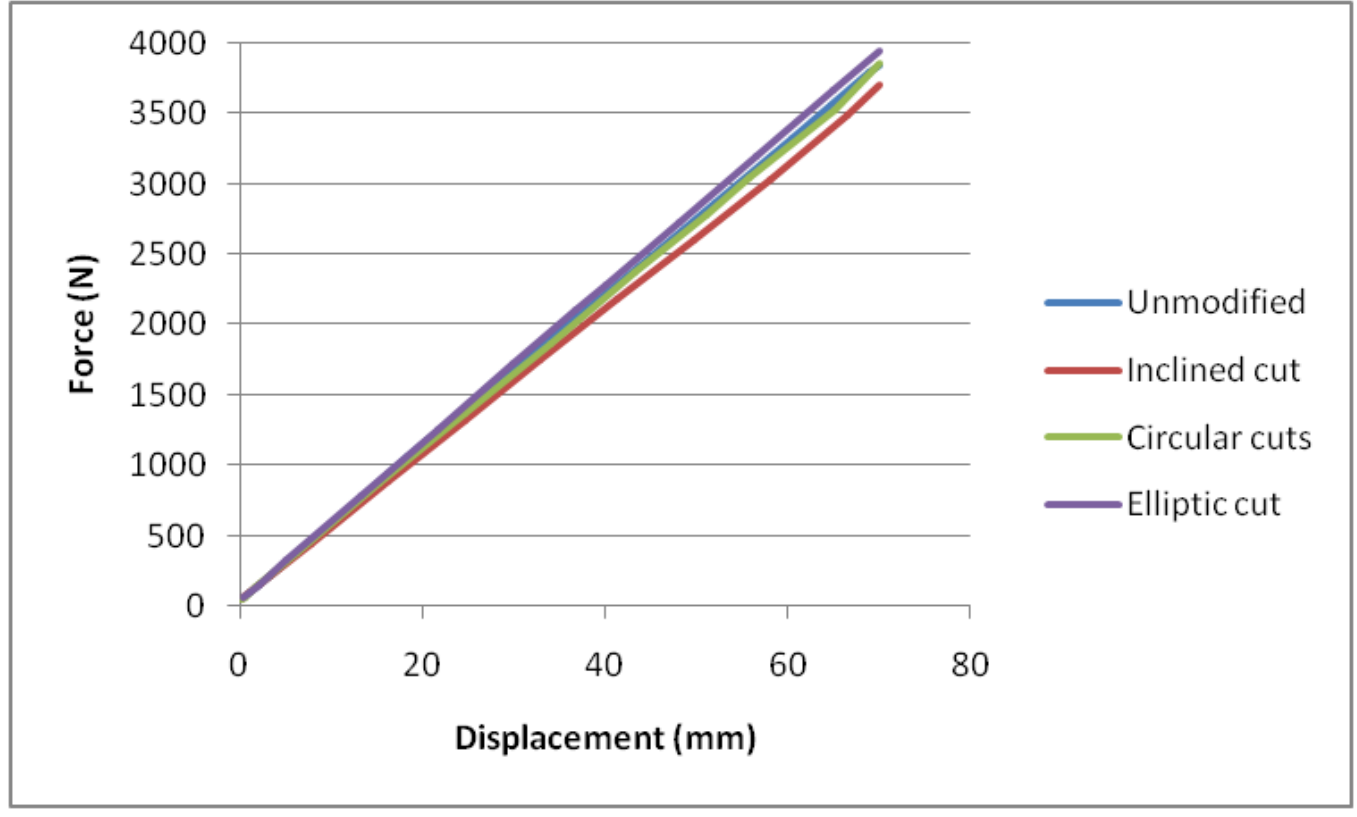

Figure 13: Load- deflection response of six- leafs spring

\subsection{Four- leafs spring}

To verify that previous findings can be drawn to other types of leaf springs, a second different model is analyzed. This spring consists of four leafs. One full length leaf, followed by three generated leafs. Characteristics of this spring are shown in Table 1. The same modifications that investigated on the above six leafs spring, are also tested on this spring.

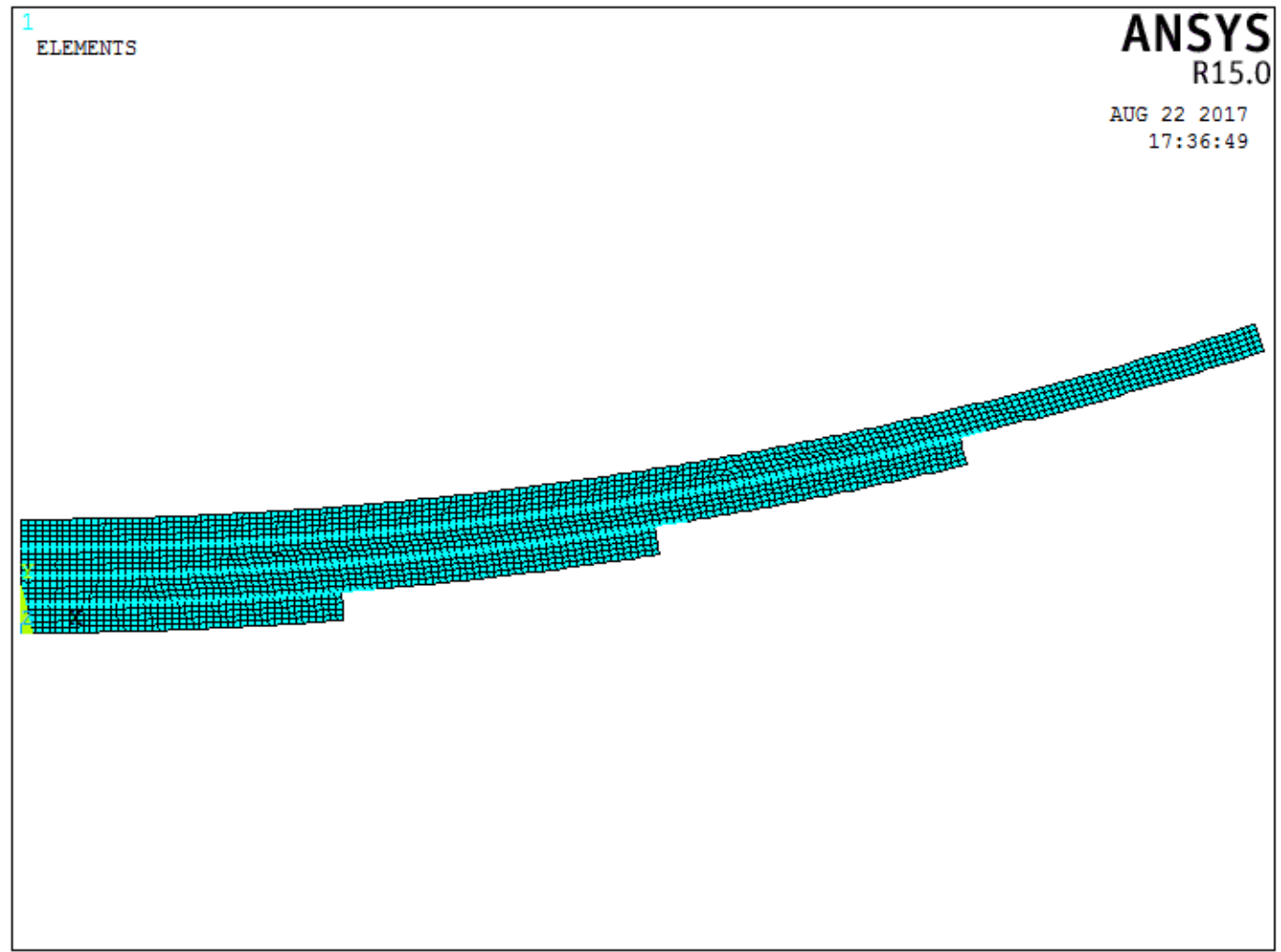

Figure 14: Four- leafs spring 


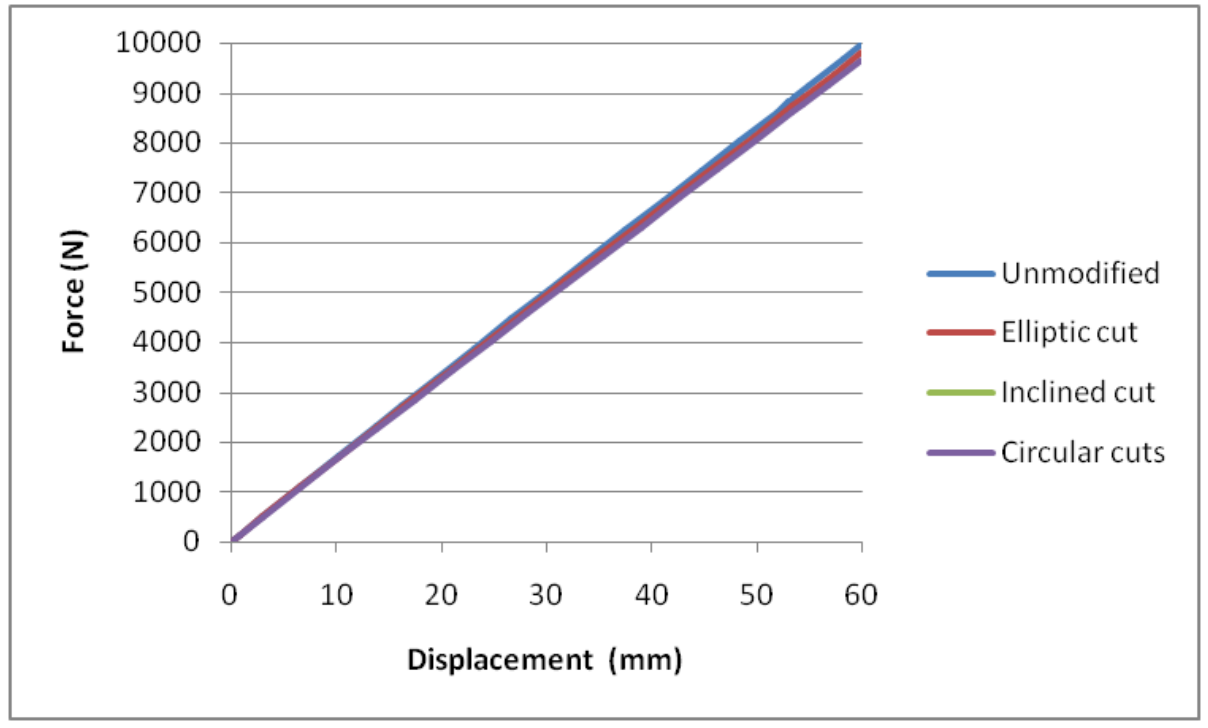

Figure 15: Load- deflection response of four- leafs spring

Table 2 Summary of results of analyzed springs.

\begin{tabular}{|c|c|c|c|c|}
\hline \multirow{2}{*}{$\begin{array}{c}\text { Type of } \\
\text { modification }\end{array}$} & \multicolumn{2}{|c|}{ Six- leafs spring model } & \multicolumn{2}{c|}{ Four- leafs spring model } \\
\cline { 2 - 5 } & $\begin{array}{c}\text { Contact } \\
\text { stress } \\
\text { MPa }\end{array}$ & $\begin{array}{c}\text { Von Mises } \\
\text { stress } \\
\text { MPa }\end{array}$ & $\begin{array}{c}\text { Contact } \\
\text { stress } \\
\text { MPa }\end{array}$ & $\begin{array}{c}\text { Von Mises stress } \\
\text { MPa }\end{array}$ \\
\hline Unmodified & 53.14 & 970.2 & 69.78 & 1104.3 \\
\hline Inclined cut & 12.76 & 714.7 & 19.86 & 875.9 \\
\hline Circular cuts & 52.68 & 981.5 & 57.96 & 1518.3 \\
\hline Elliptical cut & 27.08 & 914.7 & 63.21 & 1002.6 \\
\hline
\end{tabular}

The unmodified model is shown in Figure 14. The maximum von Mises stress is $1104 \mathrm{MPa}$, and contact pressure is about $70 \mathrm{MPa}$.

Results of analyses of this spring are shown in Table 2. Which represents a summary of maximum contact and von Mises stresses of all analyzed springs in this study are presented.

For this model, the modification of inclined cut at end of leafs model resulted dramatically dropping in the contact pressure to $19.8 \mathrm{MPa}$. Also von Mises stress reduced by $21 \%$ of original value.

The two half- circular cuts model showed mild reduction in contact pressure by $17 \%$ of original value, with a significant increase in von Mises stress.

The modification of elliptical cut also lead to some reduction in contact and von Mises stress.

Figure 15 indicates that all modifications made on this spring did not have any effect on its spring scale.

\section{Conclusions}

Due to large variety of leaf spring types and leaf distribution possibilities, it is not possible to make a general study with design recommendations for modifications in all types of leaf springs. Instead a sample design study has been carried out for specific types of leaf springs. The following notes can be concluded from this study;

1- The similarity of results of the two different types of analyzed springs indicates that results of this study can be drawn to other types of leaf springs. Detailed design study can be carried out for the specific spring, testing the types of cuts presented in this study.

2- Contact stresses of unmodified models are concentrated at leafs tip, whereas that of modified springs are rather distributed.

3- All modifications did not cause any noticeable change in spring scale.

4- The model of linear gradual profiling of the outer side of each leaf, provide best result.

\section{References}

[1]. Ashish V. Amrute, Edward Nikhil karlus, R.K.Rathore, Design and assessment of multi leaf spring, Int. $\mathbf{J}$ of research in aeronautical and mechanical engineering, 1 Issue.7, November (2013), pp: 115-124. 
[2]. Kumar Krishan and Aggarwal M.L ,A Finite Element Approach for Analysis of a Multi Leaf Spring using CAE Tools, Res.J.Recent Sci. 1(2), Feb. (2012), pp: 92-96.

[3]. Shahrukh Shamim1, Jamil Anwer, Design and optimization of automotive multi-leaf spring by finite element method,IJRAME, 2, Issue 8, (2014), pp:46-54.

[4]. Subhash Chandrabose, C. Thamotharan, P. Naveenchandran and R. Anbazhagan, Design Optimization and Analysis of a Parabolic Leaf Spring, Middle-East Journal of Scientific Research 20 (11), (2014), pp: 15901596.

[5]. Vivek Rai, Gaurav Saxena, Development of a Composite Leaf Spring for a Light Commercial Vehicle (Tata Magic), Int. Journal of Engineering Research and Applications, 3, Issue 5, Sep-Oct (2013), pp: 110-114

[6]. Jadhav Mahesh V, Zoman Digambar B, Y R Kharde, R R Kharde, Performance Analysis of Two Mono Leaf Spring Used For Maruti 800 Vehicle, IJITEE, Volume-2, Issue-1, December 2012, pp 65-67.

[7]. Ramakanth U. S. and Sowjanya K., Design and analysis of automotive multi-leaf springs using composite materials, IJMPERD, 3, Issue 1, Mar (2013), pp: 155-162

[8]. Jeremy Li, Computer- Aided Modeling and Simulation On A New Composite Leaf Spring System Design, International Joint Conferences on Systems, Computing Sciences and Software Engineering, 2011.

[9]. J. P. Karthik, K. L. Chaitanya and C. Tara Sasanka, Fatigue Life Prediction of a Parabolic Spring under Non-constant Amplitude Proportional Loading using Finite Element Method, International Journal of Advanced Science and Technology, Vol. 46, September, (2012), pp: 143-156.

[10]. Mouleeswaran Senthil Kumar, Sabapathy Vijayarangan, Analytical and Experimental Studies on Fatigue Life Prediction of Steel and Composite Multi-leaf Spring for Light Passenger Vehicles Using Life Data Analysis, Materials science (MEDŽIAGOTYRA). 13(2), (2007), pp: 141-146.

[11]. V.K.Aher, R.A.Gujar, and J.P.Wagh ,Fatigue Life Prediction of Multi Leaf Spring used in the Suspension System of Light
Commercial Vehicle, IJTARME, 1, Issue-1, (2012), pp: 71-77.

[12]. Vinkel Kumar Arora,1 Gian Bhushan,2 and M. L. Aggarwal ,Fatigue Life Assessment of 65Si7 Leaf Springs: A Comparative Study, Hindawi Publishing Corporation, International Scholarly Research Notices, Volume 2014, Article ID 607272,

[13]. A. L. Aishwarya, A. Eswara Kumar, V. Balakrishna Murthy, Free Vibration Analysis of Composite Leaf Springs, IJRMET, 4, Issue spl - 1, April 2014, pp: 9597.

[14]. Ritesh Mistry, Dynamic Analysis of A Leaf Spring, IJREAT, 2, Issue 2, Apr-May, (2014), pp: 1-4.

[15]. D.Younesian, M. S. Fallahzadeh, Numerical and Experimental Analysis of Nonlinear

Parabolic Springs Employed in Suspension System of freight cars, International Journal of Automotive Engineering, 4, Number 3, Sept (2014). 